\title{
Phenol Removal using Corona Discharge Plasma Combined with Porous Polyaniline Nanofiber
}

\section{Ahmed El-Tayeb Khalil ( $\nabla$ Ahmed_al_tayeb@aswu.edu.eg )}

Aswan University https://orcid.org/0000-0001-8719-8715

Hussain Noby

Egypt-Japan University of Science and Technology

AHMED H ELSHAZLY

Egypt-Japan University of Science and Technology

Marwa F. Elkady

Egypt-Japan University of Science and Technology

\section{Research Article}

Keywords: Non-Thermal Plasma, Corona Discharge Plasma, Industrial Water Treatment, Organic Pollution, Polyaniline Nanofiber, Phenol Removal

Posted Date: May 11th, 2021

DOl: https://doi.org/10.21203/rs.3.rs-441230/v1

License: (c) (1) This work is licensed under a Creative Commons Attribution 4.0 International License. Read Full License 


\title{
Phenol Removal using Corona Discharge Plasma Combined with Porous Polyaniline Nanofiber
}

\author{
Ahmed EL-Tayeb Khalil ${ }^{1, *}$, Hussain Noby ${ }^{2,3}$, Ahmed Hassan EL-Shazly ${ }^{3}$, Marwa Elkady ${ }^{3}$ \\ ${ }^{1}$ Electrical Engineering Department, Faculty of Energy Engineering, Aswan University, Aswan, Egypt. \\ ${ }^{2}$ Materials Engineering and Design Department, Faculty of Energy Engineering, Aswan University, Aswan, Egypt. \\ ${ }^{3}$ Chemical and Petrochemicals Engineering Department, Egypt-Japan University of Science and Technology, New \\ Borg El-Arab City, Alexandria, Egypt. \\ *Corresponding author: Ahmed_Al_Tayeb@aswu.edu.eg
}

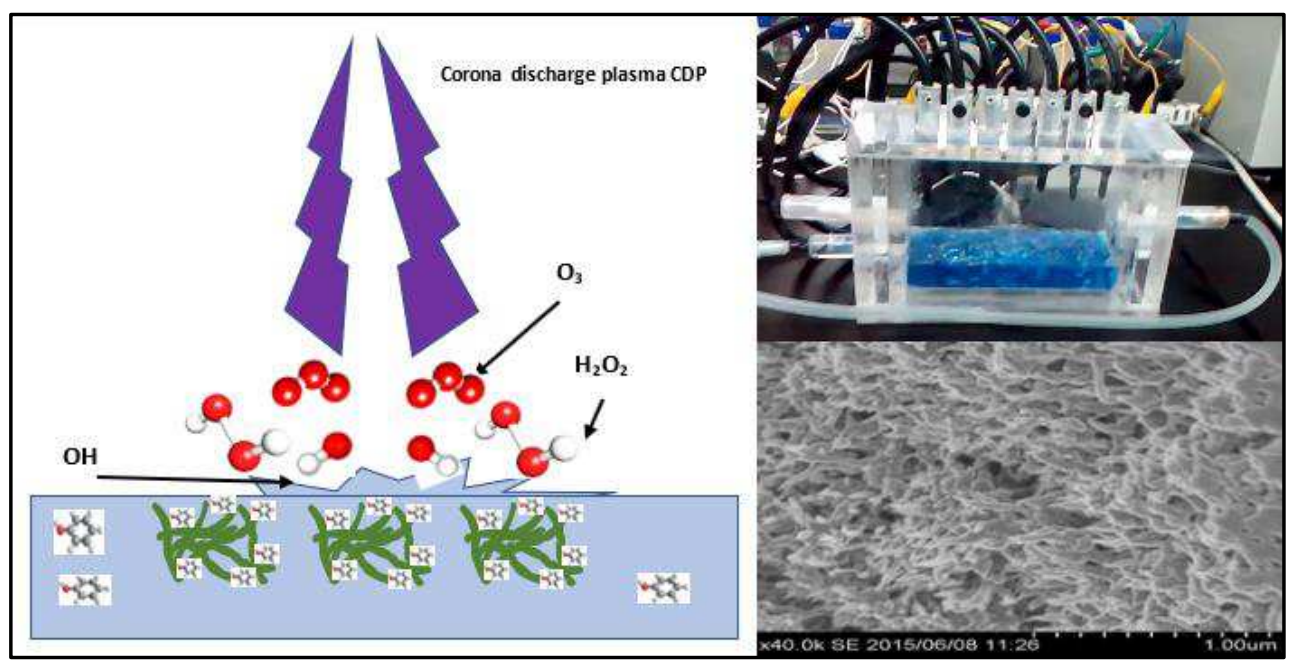

\section{Abstract}

A contemporary design for a recirculated flow dual remediation system was successfully developed for phenol remediation. The system involved Corona Discharge Plasma (CDP), accompanied by Polyaniline Nanofiber (PANNFs) as a solid adsorbent. PANNFs was obtained using simple chemical oxidation polymerization at room temperature. Different chemo-physical characterization techniques were employed to examine the produced polyaniline such as Fourier Transform Infrared spectroscopy (FT-IR), X-ray Diffraction (XRD), and Brunauer, Emmett, and Teller (BET) surface area analysis.

The primary purpose of the used PANNF powder is to facilitate the phenol degradation using plasma by collecting the phenol molecules on the surface of PANNFs. The phenol removal percentage of $99 \%$ was attained at a treatment time of 60 min using the developed dual system. Finally, a slight synergetic effect between the used two remediation processes, PANI as adsorbent and CDP treatment, was approved. PANNFs existence in the remediation system also helps to save the consumed power in degradation using CDP.

Keywords: Non-Thermal Plasma; Corona Discharge Plasma; Industrial Water Treatment; Organic Pollution; Polyaniline Nanofiber; Phenol Removal.

\section{Introduction}

Phenol and its derivatives are vastly used in various industries such as fertilizers, plastics, paints, paper and soap industries, adhesives petroleum refineries, coal gasification processes, liquefaction 
processes, and phenol-formaldehyde resins (Bakelite). Although the concentrations of phenol are a vital issue of environmental concern due to their toxicity (Seo et al. 2013, Kulkarni et al. 2013), no more than $5 \mathrm{mg} / \mathrm{L}$ phenol concentration is allowed conferring to the Environmental Protection Agency (EPA) regulations (Belaib et al. 2012). For instance, erosion of tissues, protein degeneration, paralysis of the central nervous system, and damages of kidneys, liver, pancreas are kinds of infections that could occur if a phenol contaminated water were consumed by a human body (Belaib et al. 2012, Bosi et al. 2018 and Ni et al. 2013). Therefore, regarding preserving the environmental and health quality, phenol removal from aqueous solutions is a crucial concern. Numerous techniques, such as solvent extraction, dialysis, microbial degradation, ion exchange, reverse osmosis, membrane processes, non-thermal plasma, and adsorption, were investigated for phenol removal from wastewater (Jiang et al. 2014, El-Tayeb 2016). Among the mentioned techniques, non-thermal plasma was highly considered due to its high selectivity and energy efficiency in chemical reactions compared with the thermal plasma, which needs high energy. Therefore, electrical plasma technologies for water treatment attracted an increasing interest. Significant bulk-phase reactions could be generated on the surface of the liquid by the plasma. These reactions generated at the airliquid interface resulted in oxidative reagents generation. The generated reagents, such as: $\mathrm{OH}^{*}, \mathrm{O}^{*}$, $\mathrm{O}_{2}$, and $\mathrm{H}^{*}$ and different molecules like $\mathrm{H}_{2} \mathrm{O}_{2}$ and $\mathrm{O}_{3}$, were used successfully for water decontamination (El-Tayeb et al. 2016, An et al. 2011). Coalescence of two forms of advanced removal techniques is a promising approach in wastewater treatment processes. The pulsed discharge plasma system with $\mathrm{TiO}_{2}$ photo-catalysis was combined for target pollutants oxidization in aqueous solution (Zhang et al. 2013, Iervolino et al. 2019). Also, pulsed discharge plasma with activated carbon was employed for wastewater purification and treatment (Hao et al. 2009, Jiang et al. 2013). Polyaniline (PANI) is an active conductive polymer with unique properties such as chemical stability, considerable surface area, ease in preparation, and non-toxic. Consequently, PANI was widely used in wastewater treatment (El-Tayeb et al. 2016, El-Tayeb et al. 2017, Xu et al. 2015). Accordingly, it was inspired to study the effect of non-thermal plasma degradation with PANI adsorption combination. Herein, a dual remediation system was introduced for phenol removal from aqueous solutions. The phenol solution is treated by polyaniline nanofibers (PANNFs) adsorbent before being degraded by plasma. This system examines the combination of the adsorptive removal using PANNFs with the phenol degradation using the non-thermal plasma system. The phenol degradation process was optimized experimentally by studying the change of the phenol initial concentration and the dosage of the PANNFs.

\subsection{Corona Discharge Plasma System}


The experimental setup is shown in Fig. 1 is composed of two main parts, the electrical power supply system, and non-thermal plasma-based reactor. First, the electrical power supply system consists of three parts; DC battery, Pulsed Wide Modulation (PWM) switching circuit, and an ignition coil (autotransformer). The DC battery is responsible for providing a DC voltage of $12 \mathrm{~V}$ to an electronic switching circuit PWM. The output of the PWM circuit is a pulsed voltage directed to the ignition coil, which in turn converts the low voltage to a high voltage of $15 \mathrm{KV}$. Voltage and current sensors are placed after the ignition coil and connected to an oscilloscope to show the waveforms of the voltage and current. High voltage generated is applied to the electrodes to produce the electrical discharge between the high voltage electrode and the ground one which called Corona Discharge Plasma as a type of Non-thermal Plasma technique for industrial wastewater treatment.



Fig. 1 Schematic diagram of the designed new remediation system used for phenol removal.
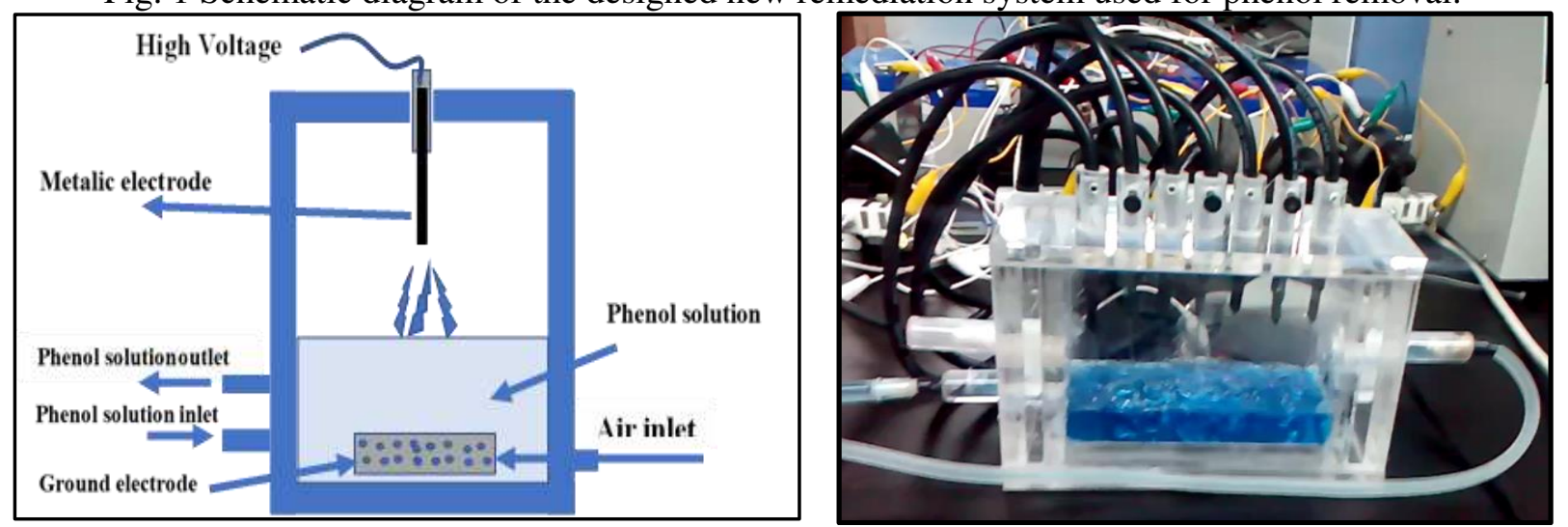

Fig. 2 Schematic diagram of the main reactor's side view.

Second, the reactor consists of a high voltage pin electrode (7 pins) fixed over a rectangle vessel (21 $* 7 * 10 \mathrm{~cm}$ ), tube as a ground electrode, recirculating water pump, and circular reservoir placed over a stirrer. The pins electrodes were fixed vertically $15 \mathrm{~mm}$ over the wastewater surface. The seven pins have $1 \mathrm{~mm}$ in diameter, $30 \mathrm{~mm}$ in height, placed in a linear pattern $15 \mathrm{~mm}$ apart of each other's, and 
connected to the high voltage cables. The ground stainless-steel tube was submerged in the liquid and perforated to be used as an air inlet for wastewater agitation. At the reservoir, the contaminated water (aqueous phenol solution) was mixed with PANI powder, stirred at $500 \mathrm{rpm}$ for a certain time, and then recirculated through the system at $150 \mathrm{~mL} / \mathrm{min}$ using a submerged water pump (without preventing water stirring). Air was pumped into the ground electrode tube using a compressor with a uniform flow rate of $0.1 \mathrm{~L} / \mathrm{min}$. The air passed from the tube to the discharge region across the wastewater vessel. Then, the air and the gases resulted from the phenol degradation passed the pipe between the discharge region and the reservoir, before being released from the reservoir.

\subsection{Polyaniline preparation}

\subsubsection{Materials}

Aniline $\mathrm{C}_{6} \mathrm{H}_{5} \mathrm{NH}_{2}$, ammonium peroxydisulfate (APS) $\left(\mathrm{NH}_{4}\right)_{2} \mathrm{~S}_{2} \mathrm{O}_{8}, \mathrm{HCl}$, ethanol, methanol, and Phenol (Sigma Aldrich, USA) were used as received.

\subsubsection{Polyaniline synthesis}

A simple chemical polymerization process with a rapid mixing technique was used to produce the nanofiber polyaniline (PANNFs). $0.2 \mathrm{M}$ aniline was dissolved in $50 \mathrm{~mL}$ of $1 \mathrm{M} \mathrm{HCl}$ solution at room temperature. Another $50 \mathrm{~mL}$ aqueous solution of $0.25 \mathrm{M}$ APS was also prepared at room temperature. The APS solution was mixed with the aniline solution at once with continuous stirring at $1000 \mathrm{rpm}$ for $1 \mathrm{hr}$. The polymerization process was kept for 24 hours at room temperature. The precipitated polymer powder was filtered, collected, and washed with $0.2 \mathrm{M}$ of $\mathrm{HCl}$, ethanol, methanol, and distilled water then separated by centrifugation for $15 \mathrm{~min}$ at $5000 \mathrm{rpm}$. Then, the produced polymer was dried overnight at $60{ }^{\circ} \mathrm{C}$.

\subsection{Characterization techniques}

The FT-IR spectra and X-ray diffraction analysis of the produced PANI were measured using an IR spectrometer (Vertex 70, Bruker Scientific Instruments, Germany) and LabX XRD-6100 (Shimadzu, Japan), respectively. Scanning Electron Microscopy (SEM, JEOL JSM 6360LA, Japan) was employed to show the produced morphology. Nitrogen adsorption/desorption isotherms at $77 \mathrm{~K}$ and Brunauer-Emmett Teller (BET) surface area tests were conducted using a Belsorp Mini II (BEl Japan Inc., Japan). The pore size distribution and the total pore volume were evaluated using the Barrett, Joyner, and Halenda (BJH) method. The classification of pores and isotherms standardized by The International Union of Pure and Applied Chemistry (IUPAC) was used in this study. The phenol concentration before and after the treatment process was measured using a UV spectrometer (HITACHI U-3900).

\subsection{Energy Consumption Evaluation}




\subsubsection{Energy Consumption}

117 A significant factor in identifying the feasibility of phenol degradation using the newly designed 118 system is the power consumption estimation for a fixed quantity of wastewater and treatment time. The consumed energy consumed per unit volume $\left(E_{c}\right)(\mathrm{J} / \mathrm{L})$ is calculated using Eq. (2).

$$
E_{c}=\frac{t * P}{V_{o}}
$$

Where $t$ is the treatment time (s), $P$ is the power (W), and $V o$ is the solution volume (L).

\section{4}

125

126

\subsubsection{Electrical Energy per Order}

Electrical energy per order $(\mathrm{EE} / \mathrm{O})$ is a vital term to estimate the consumed electrical power in the treatment process. EE/O was defined as; the electrical energy in kilowatt-hours $(\mathrm{kWh})$ required to reduce the concentration of a pollutant by 1 order of magnitude in $1 \mathrm{~m}^{3}$ of contaminated water. EE/O (in $\mathrm{kWh} / \mathrm{m}^{3}$ ) is calculated by (Sunka 2001, Wang et al. 2014):

$$
E E / O=\frac{P * t * 1000}{60 * V_{o} * \log \left({ }^{C_{i}} / C_{f}\right)}
$$

Where $C_{f}$ is the final phenol concentration $(\mathrm{mg} / \mathrm{L})$.

\subsubsection{Energy yield for phenol remediation}

The energy yield $(G)(\mathrm{g} / \mathrm{kWh})$ is defined as the amount of pollutant in grams could be decontaminated when $1 \mathrm{kWh}$ of powers is consumed. It could be calculated using the following relation, (Lukes 2005, Hayashi et al. 2014):

$$
G=\frac{C_{0} * V_{0} * D \%}{100 * P * t}
$$

Where $D \%$ is the percentage of phenol removal, $C_{o}$ in $(\mathrm{mg} / \mathrm{L}), P$ in $(\mathrm{kW})$, and $t$ (hour).

\section{RESULTS AND DISCUSSION}

PANNFs weight of $(0,0.05,0.1,0.15,0.2$, and $0.25 \mathrm{~g})$ were mixed with $400 \mathrm{~mL}$ of phenol/water solution with phenol initial concentration of $(5,10,20,40,60,80$, and $100 \mathrm{mg} / \mathrm{L})$. The mixtures were stirred at $500 \mathrm{rpm}$ continuously at room temperature. After a while, the mixture was recirculated by a pump with a flow rate of $150 \mathrm{~mL} / \mathrm{min}$ to the reactor and then exposed to the Corona Discharge Plasma System (CDPS). The reactor was extra agitated with fresh air pumped into the system with a flow rate of $0.1 \mathrm{~L} / \mathrm{min}$. Furthermore, a typical experiment was conducted using $0.25 \mathrm{~g}$ of PANNFs alone without plasma to measure the proposed synergy effect between the two phenol removal techniques. $1 \mathrm{~mL}$ of the solution was drawn After a time interval of $10 \mathrm{~min}$, and the phenol concentration was measured using a UV spectrophotometer (HITACHI U-3900) at a wavelength of $265 \mathrm{~nm}$. The remediation efficiency RE of the dual system was calculated by: 
Where $C_{o}$ and $C_{t}$ are the initial phenol concentration $[\mathrm{mg} / \mathrm{L}]$ and the concentration at time $t$, respectively.

\section{$154 \quad 3.1$ Polyaniline characterization}

\section{3.1.1 Morphology of PANI}

156 The morphology of the prepared PANI was observed by SEM. Figure 3a showed that nanofibers were

157 obtained with an average diameter of $40 \mathrm{~nm}$. Furthermore, it was noticed that the fibers were directed 158 in one direction with a rough surface. The rough surface may help increase the surface area which 159 plays a crucial role in the adsorption process.

\section{$160 \quad$ 3.1.2 Crystalline structure}

161 As shown in Fig. 3b, a classic semi-crystalline structure with a considerable agreement with what 162 reported before (Ai et al. 2010, Ayad et al. 2013, Noby et al. 2017). The formed crystals may result 163 from the existence of hydrogen bonds between amines and imines in the longitudinal direction of the 164 polyaniline chain. The XRD pattern of PANI shows two peaks: one centered at $2 \theta=21^{\circ}$, which could 165 be ascribed to a periodicity parallel to the PANI polymer chain, and the other at $25.7^{\circ}$ could be ascribed to a periodicity perpendicular to the PANI chain (Noby et al. 2016).

\subsubsection{Chemical structure}

168 The Fourier transform infrared spectra (FT-IR) of PANNFs were shown in Fig. 3c. The FT-IR spectra 169 agree with the previously reported results (Noby et al.2018, Noby et al. 2019, Kaneko 1994). The 170 characteristic peaks of the benzenoid and quinoid units at 1532 and $1640 \mathrm{~cm}^{1}$, respectively, were 171 identified.
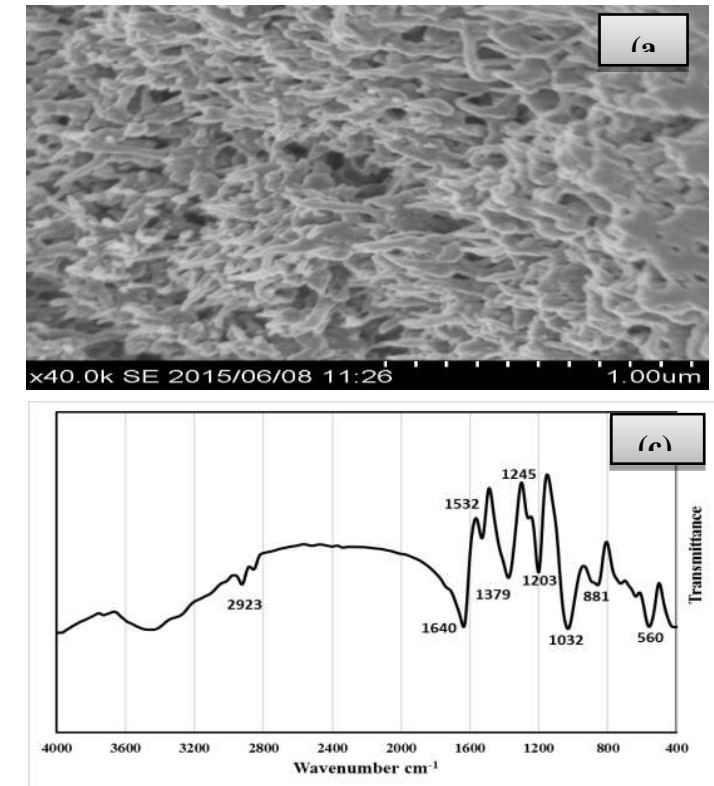
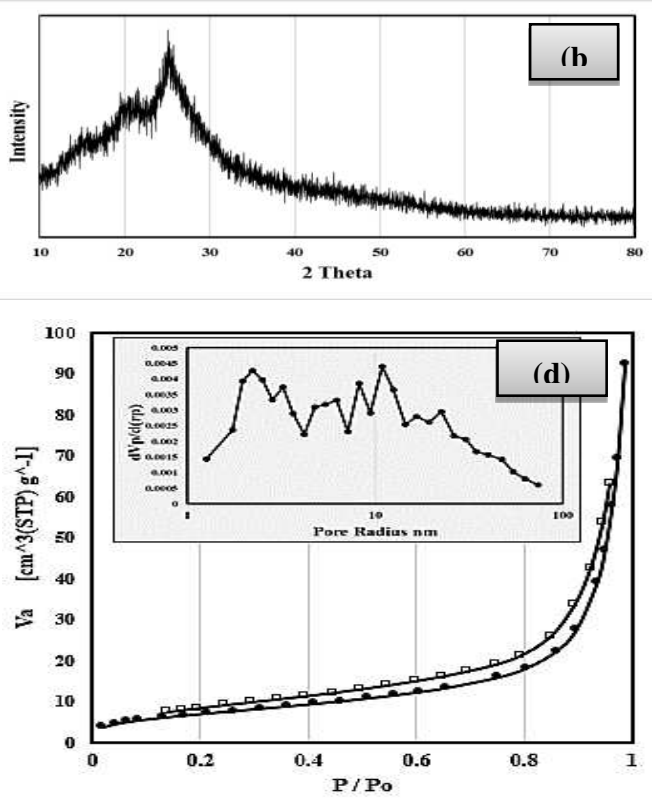

Fig. 3 (a) SEM image, (b) XRD, (c) FT-IR, and (d) $\mathrm{N}_{2}$ adsorption/desorption isotherm and pore size distribution for the produced PANI. 
175 The band at $1379 \mathrm{~cm}^{-1}$ was attributed to the $\mathrm{C}-\mathrm{N}$ stretching vibration of the secondary aromatic 176 amine. The peak at $695 \mathrm{~cm}^{-1}$ is accompanied by the aromatic $\mathrm{C}-\mathrm{H}$ out-of-plane bending vibrations.

177 The band at $1203 \mathrm{~cm}^{-1}$ corresponds to $\mathrm{N}=\mathrm{Q}=\mathrm{N}$, where $\mathrm{Q}$ represents the quinoid unit. The band at 881

$178 \mathrm{~cm}^{-1}$ is associated with $\mathrm{C}-\mathrm{C}$ and $\mathrm{C}-\mathrm{H}$ for the benzenoid unit.

\section{$179 \quad$ 3.1.4 Surface area and pore size of the synthesized PANI}

180 BET surface area and average pore size curves of the attained PANNFs are displayed in Fig. 3d. The 181 BET surface area was $26.42 \mathrm{~m}^{2} / \mathrm{g}$ accompanied by hysteresis loop $\mathrm{H}_{3}$ type, which means that the 182 pores were slit-shaped (Noby et al. 2019, Rather et al. 2015). Additionally, PANI has a wide pore 183 size distribution (diameters from 1.4 to $90 \mathrm{~nm}$ ), which may be considered as macroporous structures 184 according to the IUPAC pore classification.

\section{$185 \quad 3.2$ Non-thermal plasma system characterization}

186 The non-thermal plasma system was characterized by measuring the pulsed high voltage obtained 187 from the ignition coil. The waveform of the high voltage and corona current, from the ignition coil to 188 the remediation system, were measured by using a high voltage probe (Tektronix P6015A) and a 189 current probe (Tektronix A6021), respectively. A digital storage oscilloscope (Tektronix TDS2014) 190 was also used to display the waveforms. As shown in Fig. 4, a pulsed high voltage of $15 \mathrm{kV}$ was 191 measured with the frequency of $100 \mathrm{~Hz}$, approximately period time of $10 \mathrm{~ms}$, rise time equal 70.46 $192 \mu \mathrm{s}$, positive width $8.62 \mathrm{~ms}$, and negative width $1.376 \mathrm{~ms}$. This $15 \mathrm{kV}$ was sufficient to generate a 193 considerable number of diverse radicals and active species (El-Tayeb et al. EEEIC 2015, El-Tayeb et 194 al. EEEIC 2016). These species are the hydroxyl radical $\left(\mathrm{OH}^{*}\right)$ and hydrogen atoms $(\mathrm{H})$ from water 195 molecules. Also, humid air exposure to plasma generates ozone $\left(\mathrm{O}_{3}\right)$, singlet oxygen $(\mathrm{O})$, hydrogen 196 peroxide $\left(\mathrm{H}_{2} \mathrm{O}_{2}\right)$, and hydroperoxyl radical $\left(\mathrm{HO}_{2}\right)$ (Wang et al. 2008, Grabowski et al. 2006).

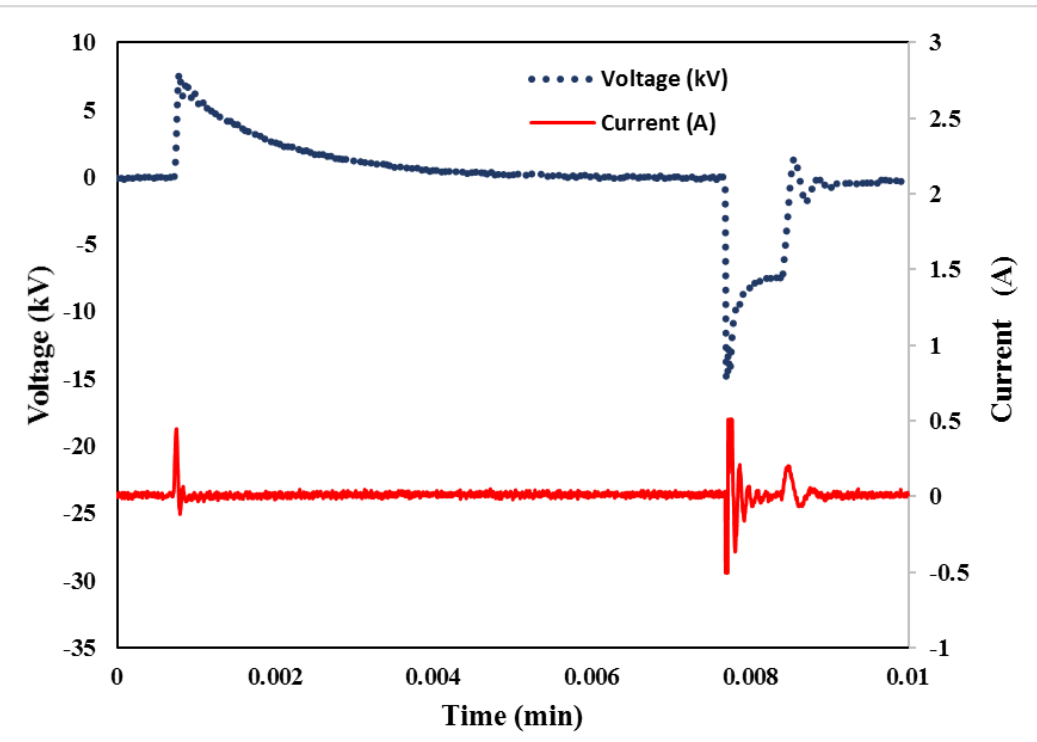

Fig. 4 Signal used in Corona Discharge Plasma

\subsection{System performance for phenol remediation}


Regarding the investigation of PANNFs addition to the plasma system on the phenol removal process, different weights of PANNFs were mixed with $400 \mathrm{~mL}$ of various concentrations of phenol/water solutions. The remediation process time was kept at $60 \mathrm{~min}$ for all mixtures. Moreover, the energy consumed per unit volume, EE/O, and the energy yield for decolorization of phenol were examined for each parameter.

\subsubsection{Effect of PANI addition}

The effect of PANI presence was evaluated by fixing the initial concentration of phenol as $20 \mathrm{mg} / \mathrm{L}$ for all experiments at room temperature. Fig. 5 shows the phenol removal efficiency with time at different PANNFs weights. Generally, a rise in the phenol degradation efficiency was noticed with the increase of the PANNFs mass added. The results show that using plasma alone $(0.0 \mathrm{mg} / \mathrm{L}$ PANNFs) removal of $92 \%$ of the initial phenol can be achieved within $60 \mathrm{~min}$, while at the same time, 98\% removal can be achieved using the dual system plasma and PANNFs of $250 \mathrm{mg} / \mathrm{L}$. This may be referred to as the phenol adsorption onto the PANNFs surface. Furthermore, augmenting the amount of PANNF improved the active surface area, which was able to adsorb more phenol molecules. When 0.25 g PANNFs was tested alone for the phenol removal (without plasma application), very low percentage removal was obtained. The maximum phenol removal was $5.7 \%$ after one hour of treatment.

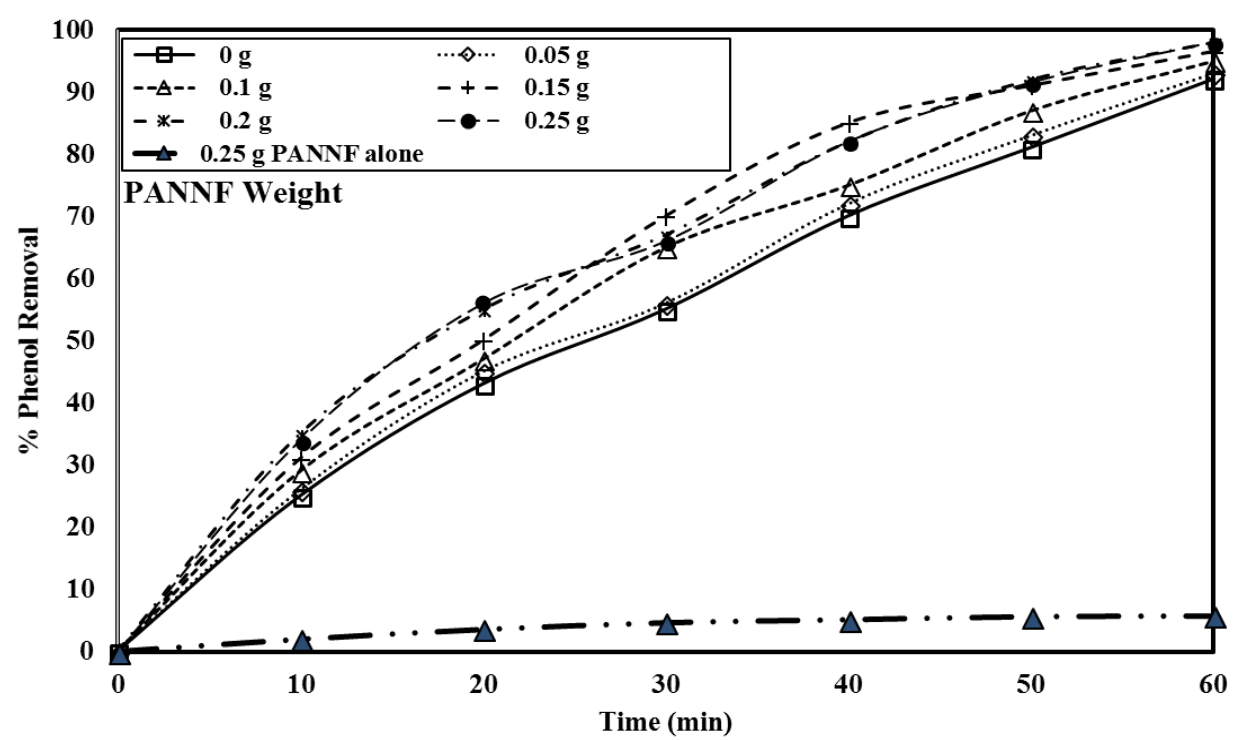

The percentage removal of phenol using both removal techniques was always slightly more than the summation of the PANNFs and plasma alone systems. Accordingly, it could be concluded that there is a slight synergy effect between the two remediation systems. The plasma may affect the PANNFs surface by breaking the bond between the PANI chains and the chlorine atom, which may, in turn, increase the porosity or surface area of PANI. 
Energy yield and EE/O for the phenol degradation process were shown in Fig. 6 and 7.

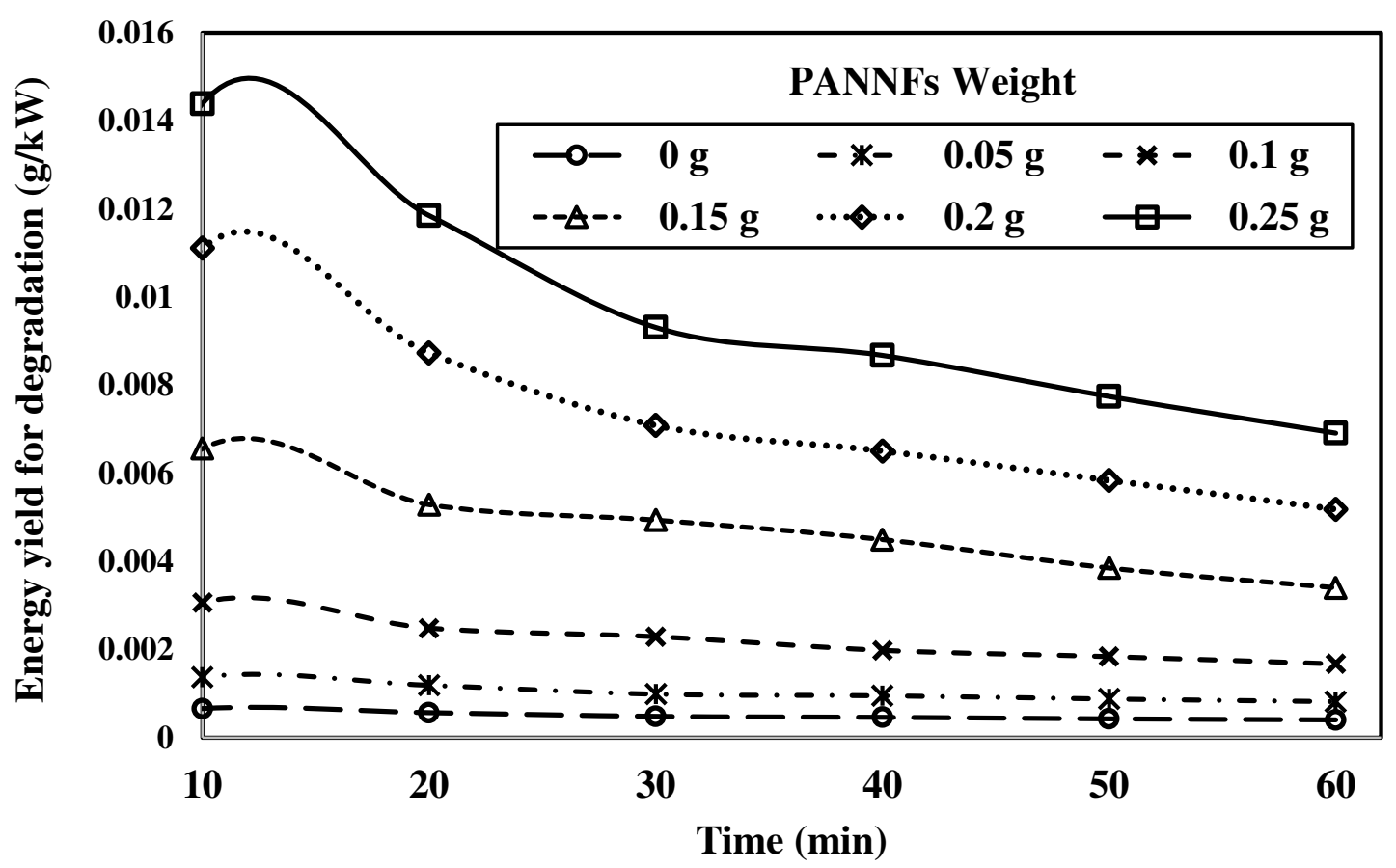

Fig. 6 The energy yield with different PANNF amounts at initial phenol concentration of 20 [mg/L].

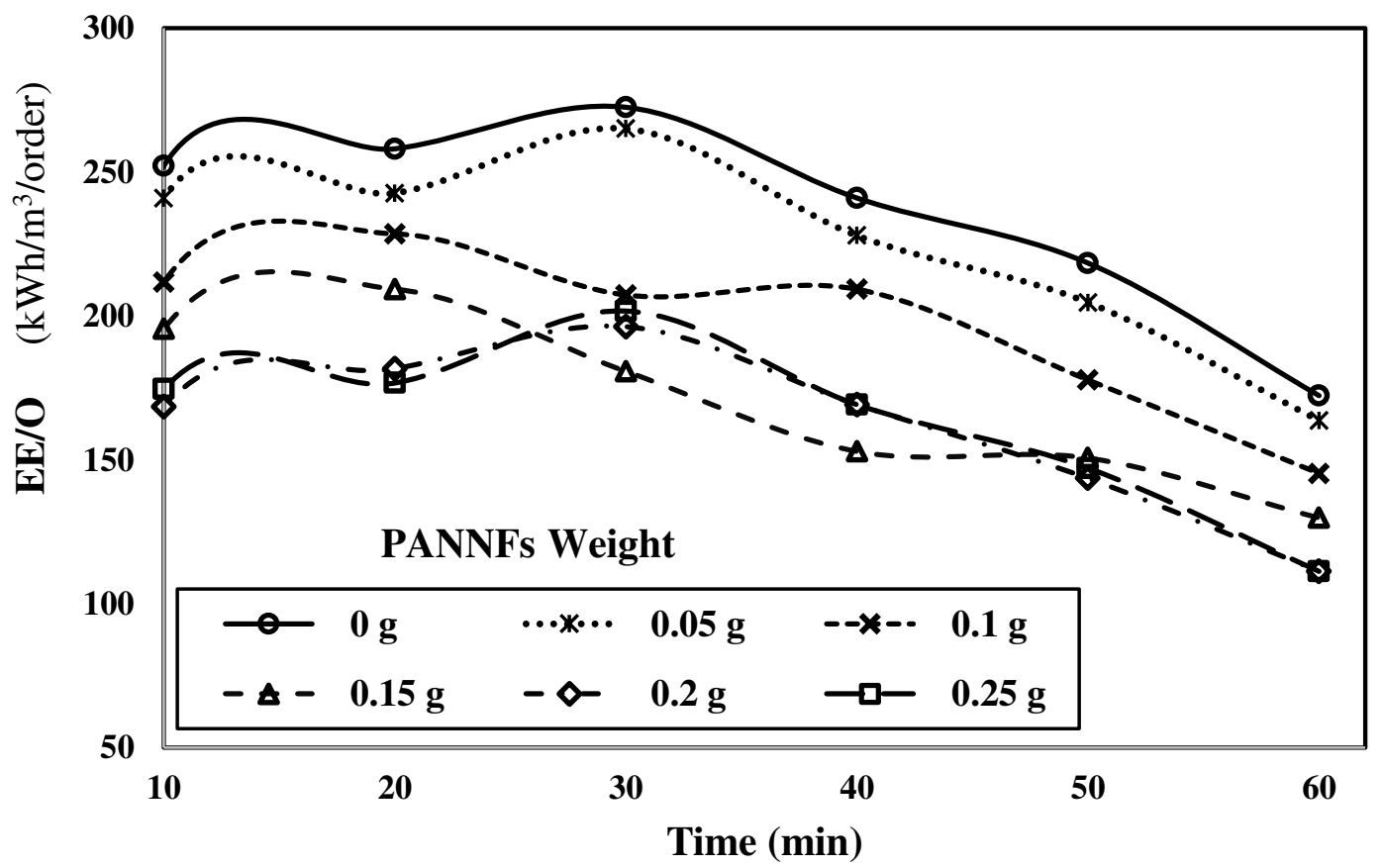

Fig. 7 EE/O with different PANNF amounts at initial phenol concentration of $20 \mathrm{mg} / \mathrm{L}$.

233 It was observed that a better energy yield was attained with the increase of PANNFs addition. For

234 instance, after 60 min of treatment using the duel system (using $0.25 \mathrm{~g}$ of PANNFs), a dramatic

235 increase in the energy yield was noticed in comparison with the plasma alone system was acquired.

236 Generally, the energy yield changed proportionally with the percentage of decontamination D, as 237 described in Eqn. 4. The addition of PANNFs represents an active surface which adsorbed more 238 phenol. Moreover, plasma helps increase the PANNFs surface area by releasing the chlorine from the 
polyaniline chains, which may help increase the phenol absorption. Based on Fig. 7, it was observed 240 that the EE/O decreased with the increase of PANNFs dosage. This may be because the system must remove much more phenol when the initial concentration was high. Also, releasing chlorine ions (widely used in water purification) may help purify the water.

\subsubsection{Effect of initial phenol concentration}

To investigate the effect of the initial concentration of phenol on the overall degradation process, the initial concentration of phenol was changed as $(5,10,20,40,60,80$, and $100 \mathrm{mg} / \mathrm{L})$ and a fixed amount $(0.2 \mathrm{~g})$ of PANNFs was employed. Figure 8 shows the phenol removal efficiency with time at different initial phenol concentrations. In general, a reduction in the phenol degradation efficiency was noticed with the increase of the phenol concentration. The degradation efficiency was $99 \%$ when $5 \mathrm{mg} / \mathrm{L}$ phenol concentration solution was used while it diminished to $84 \%$ when $100 \mathrm{mg} / \mathrm{L}$ phenol concentration was employed in a 60 min experiment. It seems to be reasonable for the dual remediation system to reach this high efficiency in the case of low phenol concentration because of the small amount of the phenol molecules. Besides, the system may need more time to reach the mentioned high efficiency in case of high phenol concentration to get rid of all the contaminant 256 molecules.

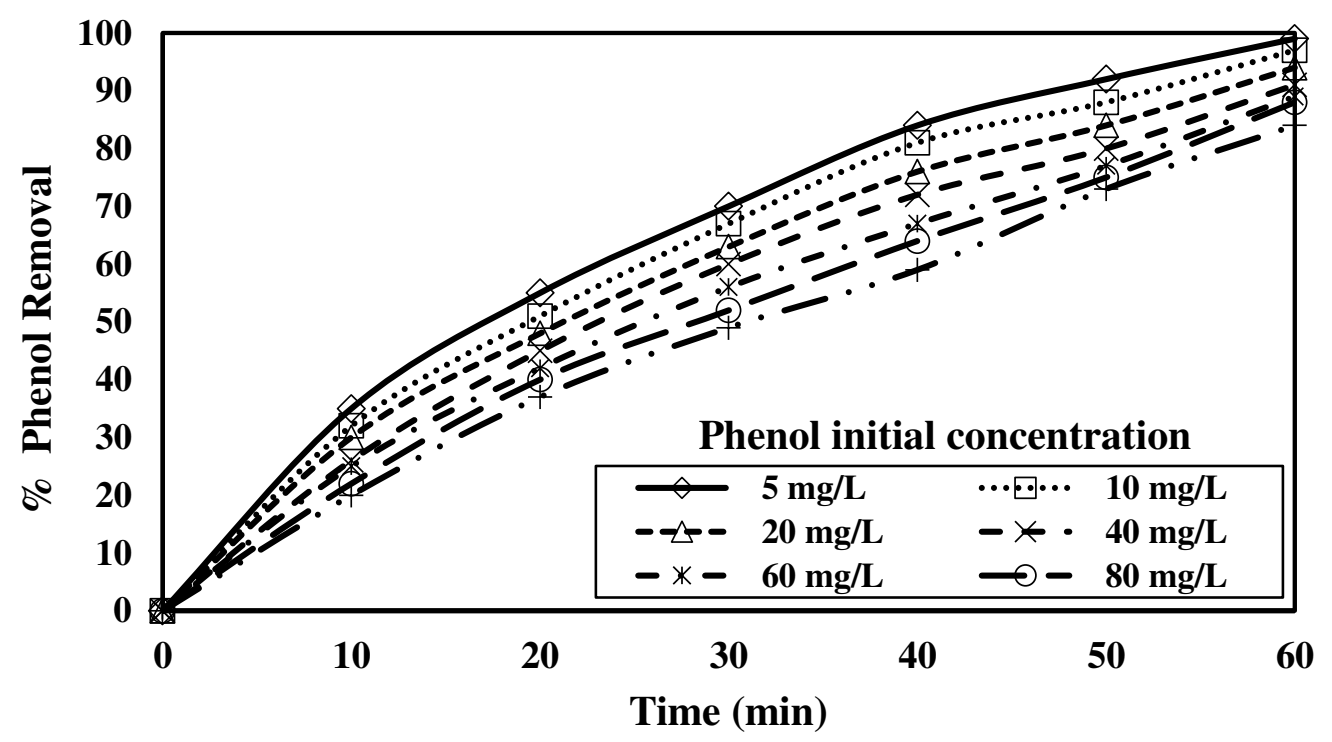

Fig. 8 Phenol removal efficiency with different phenol concentration $0.2 \mathrm{~g}$ of PANNF.

The energy yield for degradation was shown in Fig. 9. It was observed that higher energy yield required with the higher phenol initial concentration. The used corona discharge plasma directly degrades the phenol molecules. As it is known, phenol molecule includes a phenyl ring $\left(-\mathrm{C}_{6} \mathrm{H}_{5}\right)$ linked to a hydroxyl group $(-\mathrm{OH})$, so the direct plasma treatment releases the hydroxyl group. Accordingly, the more phenol concentration leads to more hydroxyl molecules released, i.e. more 
radicals, which is desired for better phenol removal. In turn, the energy yield increases. Although, the 266 higher phenol concentration, the lower phenol percentage removal obtained, the increase in the radicals is more than the reduction in the overall removal percentage.

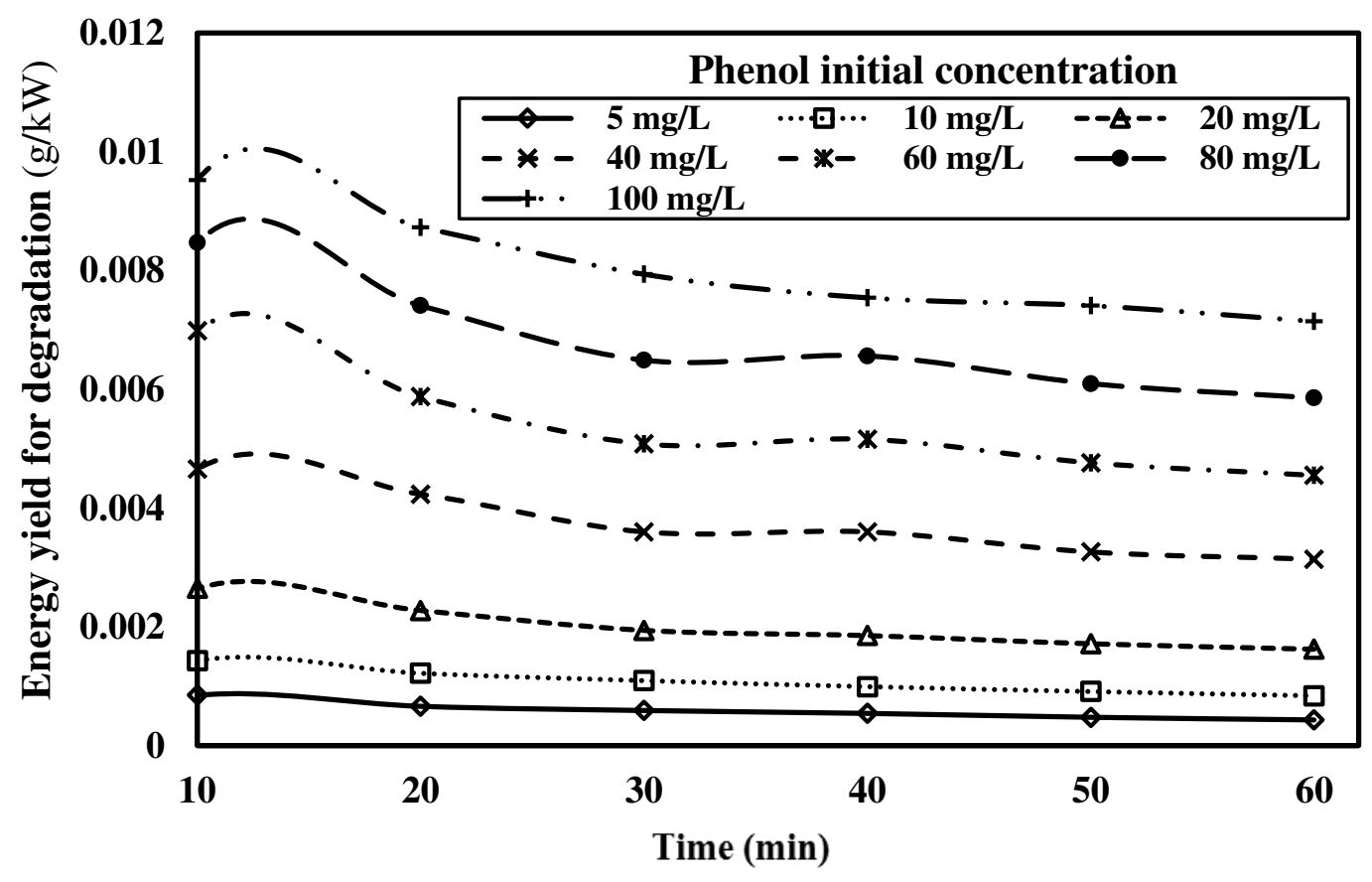

Fig. 9 Energy yield of degradation with different phenol initial concentrations at $0.2 \mathrm{~g}$ of PANNF. Figure 10 showed the Electrical Energy per Order EE/O change with the time at different phenol initial concentrations. It was found that the EE/O increased with the enlargement of the initial phenol concentration. This is attributed to the increase in the concentration of $\mathrm{OH}$ radicals due to the phenol degradation when it exposed to the plasma.

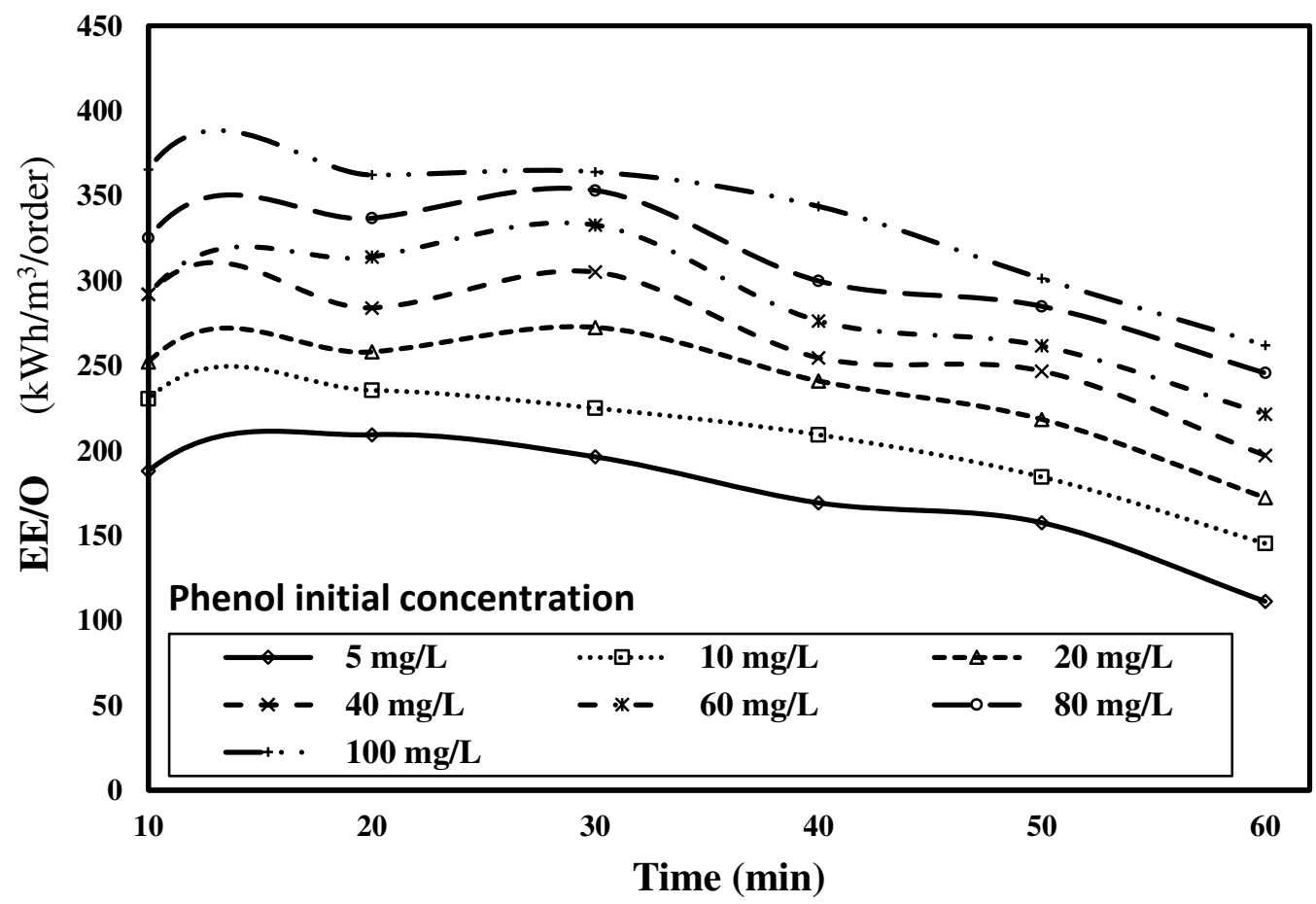

Fig. $10 \mathrm{EE} / \mathrm{O}$ with time at different phenol initial concentrations using $0.2 \mathrm{~g}$ of PANNF. 
Generally, ozone is generated in a two-steps process (Eqs. 5 and 6) when non-thermal plasma is applied to air, as a process gas, at atmospheric pressure and room temperature. These two steps are electrons utilization for $\mathrm{O}_{2}$ molecules dissociation and described as follows (Wang et al. 2008):

$$
\begin{gathered}
e ́+O_{2} \rightarrow 2 O+e ́ \\
O+O_{2}+M \rightarrow O_{3}+M
\end{gathered}
$$

Where $M$ is a third collision partner involving: $\mathrm{O}, \mathrm{O}_{2}, \mathrm{O}_{3}$, or $\mathrm{N}_{2}$. Onto the liquid-plasma surface, another productive and desired reaction occurs due to plasma presence. This reaction generates $\mathrm{OH}$ radicals due to the exposer of gaseous water molecules and radical $O$, and it may follow the reaction in Eq. 7 (An 2011). Also, $\mathrm{H}_{2} \mathrm{O}_{2}$ may be generated due to the combination of $\mathrm{OH}$ radicals, as described in Eq. 8 (Wang et al. 2008).

$$
\begin{aligned}
& \mathrm{H}_{2} \mathrm{O}+\dot{e} \rightarrow 2 \mathrm{OH} \\
& \mathrm{OH}+\mathrm{OH} \rightarrow \mathrm{H}_{2} \mathrm{O}_{2}
\end{aligned}
$$

The $\mathrm{OH}, \mathrm{H}_{2} \mathrm{O}_{2}$, and $\mathrm{O}_{3}$ radicals may be considered as the active primary radicals in the phenol degradation process (Grabowski et al. 2006, Iervolino et al. 2019).

\subsubsection{Degradation mechanism}

293 Phenol degradation using plasma may follow several mechanisms. One of the proposed mechanisms

294 for the phenol degradation process is the formation of carbon dioxide and water passing some 295 intermediate components. The hydroxyl group may play a vital role in this degradation process 296 (Zhang 2013, Wang et al. 2008). Catechol and hydroquinone are the core primary by-products of phenol, which formed via " $\mathrm{OH}$ reaction with the aromatic ring at the ortho or para-positions.



Fig. 11 Schematic diagram for the proposed phenol degradation process mechanisms using the developed dual remediation system. 
302 Furthermore, the redox reaction of hydroquinone produced 1,4-benzoquinone while the unstable

303 catechol transformed into 1,2-benzoquinone. A different mechanism was also proposed to describe 304 the degradation process using the "OH group. In this second case, aliphatic by-products (formic acid, 305 oxalic acid, and aldehydes, etc.) were produced by the continuous oxidation of the aromatic rings. All 306 the produced by-products were mineralized into carbon dioxide and water at the end of reactions. 307 These two mechanisms are illustrated in Fig. 11.

\section{Conclusion}

310 A dual remediation system utilizes two different removal techniques for phenol degradation; non311 thermal plasma accompanied by adsorption of phenol onto the surface of polyaniline nanofiber 312 PANNFs was designed. Upon the results, the prepared polyaniline showed a nanofibrous structure 313 with fibers of an average diameter of $40 \mathrm{~nm}$ and a surface area of $26.42 \mathrm{~m}^{2} / \mathrm{g}$. The phenol degradation 314 efficiency of $92 \%$ was obtained in $60 \mathrm{~min}$ when plasma treatment was used alone, while $98 \%$ phenol 315 was removed when $0.25 \mathrm{~g}$ of PANNFs was employed (20 mg/L initial phenol concentration). 316 Furthermore, the dual remediation system lowered the consumed energy by $30 \%$ (according to the 317 EE/O calculations). Generally, a slight synergistic effect between the non-thermal plasma oxidation 318 and PANI adsorption techniques was recorded. PANI surface captured the phenol molecules and may 319 make it easy for plasma to degrade the collected phenol molecules instead of scattered molecules.

\section{Ethical Approval}

$321 \quad$ Not applicable

\section{Consent to Participate}

323 Not applicable

\section{Consent to Publish}

325 Not applicable

\section{Authors Contributions}

327 Dr. Ahmed EL-Tayeb: First and soul author of the paper in part of corona discharge plasma work, 328 drafted the paper and revised the manuscript.

329 Dr. Hussain Noby: Edited and contributed in some section in write up. In addition, contributed in part 330 of polyaniline nanofiber PANNFs work

331 Prof. Ahmed Hassan EL-Shazly: Project leader and edited and contributed sections of the manuscript.

332 Prof. Marwa Elkady: Assist in Project, edited and contributed sections of the manuscript.

\section{Funding}

334 Not applicable 


\section{Competing Interests}

336 The authors declare that they have no competing interests.

\section{7}

338

\section{Availability of data and materials}

All data generated or analyzed during this study are included in this published article.

\section{References:}

A. El-Tayeb, A. H. El-Shazly and M. F. Elkady, "Impacts of Different Salts on the Degradation of Acid Blue 25 Dye Using Non-Thermal Plasma", The 16th IEEE International Conference on Environment and Electrical Engineering (EEEIC 2016), Florence, Italy, 7-10 June, (2016).

A. El-Tayeb, A. H. El-Shazly and M. F. Elkady, "Investigation the Influence of Different Salts on the Degradation of Organic Dyes Using Non-Thermal Plasma," Energies 2016, 9(11), 874; DOI:10.3390/en9110874.

A. El-Tayeb, A. H. El-Shazly, M. F. Elkady, and A. Abdel-Rahman, "Simulation and Experimental Study for Degradation of Organic Dyes Using Dual pin-to-plate Corona Discharge Plasma reactors for Industrial Wastewater Treatment," Contrib. Plasma Phys., 56, 855-869, DOI: 10.1002/ctpp.201500080, (2016).

A. El-Tayeb, A.H. El-Shazly, M.F Elkady, A. Abdel-Rahman, "Non-thermal plasma as a new advanced technique for intensifying the industrial wastewater treatment," Desalination and Water Treatment 61 (2017) 230-239 DOI: 10.5004/dwt.2016.11343.

A. El-Tayeb, A.H. El-Shazly, M.F. Elkady, and A. Abdel-Rahman, "Decolorization of Acid Blue 25 Dye by Non-Thermal Plasma Advanced Oxidation Process for Industrial Wastewater Treatment", The 15th IEEE International Conference on Environment and Electrical Engineering (EEEIC 2015), Rome, Italy, June 10-13, 2015.

A. El-Tayeb, A.H. El-Shazly, M.F. Elkady, and A. Abdel-Rahman, "Investigation of the Decolorization Efficiency of Two Pin-to-Plate Corona Discharge Plasma System for Industrial Wastewater Treatment," Plasma Phys. Rep. 42: 887-899. DOI: 10.1134/S1063780X16090026, (2016).

A., S. Rather, A. El-Shazly, Sh. F. Zaman, M. A. Daous, A. A. Al-Zahrani, Preparation of activated carbon from fly ash and its application for CO2 capture, Korean J. Chem. Eng, 32(4), (2015).

B. Jiang, J. Zheng, Sh. Qiu, M. Wu, Q. Zhang, Z. Yan, Q. Xue, Review on electrical discharge plasma technology for wastewater remediation, Chemical Engineering Journal, 236, 348-368 (2014).

B. Jiang, J. Zheng, X. Lu, Q. Liu, M. Wu, Z. Yan, Sh. Qiu, Q. Xue, Z. Wei, H. Xiao, M. Liu, Degradation of organic dye by pulsed discharge non-thermal plasma technology assisted with modified activated carbon fibers, Chemical Engineering Journal 215-216, 969-978 (2013).

C. $\mathrm{Xu}, \mathrm{H}$. Chen, and F. Jiang, "Adsorption of perflourooctane sulfonate (PFOS) and perfluorooctanoate (PFOA) on polyaniline nanotubes," Colloids Surfaces A Physicochem. Eng. Asp., vol. 479, pp. 60-67, 2015.

F. Belaib, A. Meniai, M. Lehocine, Elimination of Phenol by Adsorption onto Mineral / Polyaniline Composite Solid Support Mineral / Polyaniline Composite Solid, Energy Procedia 18, 1254 1260 (2012).

F. J. Bosi, F. Tampieri, E. Marotta, R. Bertani, D. Pavarin, C. Paradisi, Characterization and comparative evaluation of two atmospheric plasma sources for water treatment, Plasma Process and Polymers;15:e1700130, https://doi.org/10.1002/ppap.201700130, (2018).

G. An, Y. Sun, T. Zhu, X. Yan, "Degradation of phenol in mists by a non-thermal plasma reactor," Chemosphere 84, 1296-1300, (2011). 
G. Iervolino, V. Vaiano, V. Palma, "Enhanced removal of water pollutants by dielectric barrier discharge nonthermal plasma reactor," Separation and Purification Technology 215, 155-162, (2019).

G. Ni, G. Zhao, Y. Jiang, J. Li, Y. Meng, X. Wang, Steam Plasma Jet Treatment of Phenol in Aqueous Solution at Atmospheric Pressure. Plasma Processes and Polymers, 10: 353-363. doi:10.1002/ppap.201200155, (2013).

H. Noby, A.H. El-Shazly, M.F. Elkady, M. Ohshima, Adsorption Profiles of Acid Dye using Synthesized Polyaniline Nanostructure with Different Morphologies, Chemical Engineering Journal of Japan, 50(3):170-177 (2017).

H. Noby, A.H. El-Shazly, M.F. Elkady, M. Ohshima, Investigation of the Parameters affecting CO2assisted Polyaniline Polymerization, MATEC Web of Conferences, 69, 04001 (2016).

H. Noby, A.H. El-Shazly, M.F. Elkady, M. Ohshima, Novel preparation of Self-assembled HCldoped Polyaniline Nanotubes using compressed CO2-assisted Polymerization, Polymer 156, (2018), 71-75.

H. Noby, A.H. El-Shazly, M.F. Elkady, M. Ohshima, Strong Acid Doping for the Preparation of Conductive Polyaniline Nanoflowers, Nanotubes, and Nanofibers, Polymer, 182, (2019), 121848.

H. Seo, S. Ameen, M. Akhtar, M. Shin, Structural, morphological, and sensing properties of layered polyaniline nanosheets towards hazardous phenol chemical, Talanta 104, 219-227, (2013).

H. Wang, J. Li, X. Quan, Y. Wu, Enhanced generation of oxidative species and phenol degradation in a discharge plasma system coupled with $\mathrm{TiO} 2$ photocatalysis, Applied Catalysis B: Environmental 83, 72-77, (2008).

J. Wang, K. Zhang, L. Zhao, Sono-assisted synthesis of nanostructured polyaniline for adsorption of aqueous Cr(VI): Effect of protonic acids, Chemical Engineering Journal 239 (2014) 123-131.

K. Kaneko, Determination of pore size and pore size distribution. 1. Adsorbents and catalysts, J. Membrane Sci. 96, 59-89 (1994).

L. Ai, J. Jiang, R. Zhang, Uniform polyaniline microspheres: A novel adsorbent for dye removal from aqueous solution, Synthetic Metals 160 (2010) 762-767.

L. R. Grabowski, E. M. van Veldhuizen, A. J. M. Pemen, W. R. Rutgers, Corona above water reactor for the systematic study of aqueous phenol degradation, Plasma Chemistry, and Plasma Processing, Vol. 26, No. 1, (2006).

M. Ayad, G. El-Hefnawy, S. Zaghlol, Facile synthesis of Polyaniline nanoparticles; its adsorption behavior, Chemical Engineering Journal 217 (2013) 460-465.

P. Lukes and B. R. Locke, Degradation of Substituted Phenols in a Hybrid Gas-Liquid Electrical Discharge Reactor, Industrial \& Engineering Chemistry Research 44, 2921, (2005).

P. Sunka, Pulse electrical discharges in water and their applications, Physics of Plasmas 8, 2587 (2001).

S. Kulkarni, R. Tapre, S. Patil, M. Sawarkar, Adsorption of Phenol from Wastewater in Fluidized Bed Using Coconut Shell Activated Carbon, Procedia Engineering 51, 300 - 307 (2013).

X. Hao, X. Zhang, L. Lei, Degradation characteristics of toxic contaminant with modified activated carbons in an aqueous pulsed discharge plasma process, CARBON 47, 153 - 161 (2009).

Y. Hayashi, E. Wahyudiono, S. Macmudah, N. Takada, H. Kanda, K. Sasaki, and M. Goto, Decomposition of methyl orange using pulsed discharge plasma at atmospheric pressure: effect of the different electrode, Jpn. J. Appl. Phys. 53 1-8, (2014).

Y. Zhang, Q. Xin, Y. Cong, Q. Wang, B. Jiang, Application of TiO2 nanotubes with pulsed plasma for phenol degradation, Chemical Engineering Journal 215-216, 261-268 (2013). 
Figures

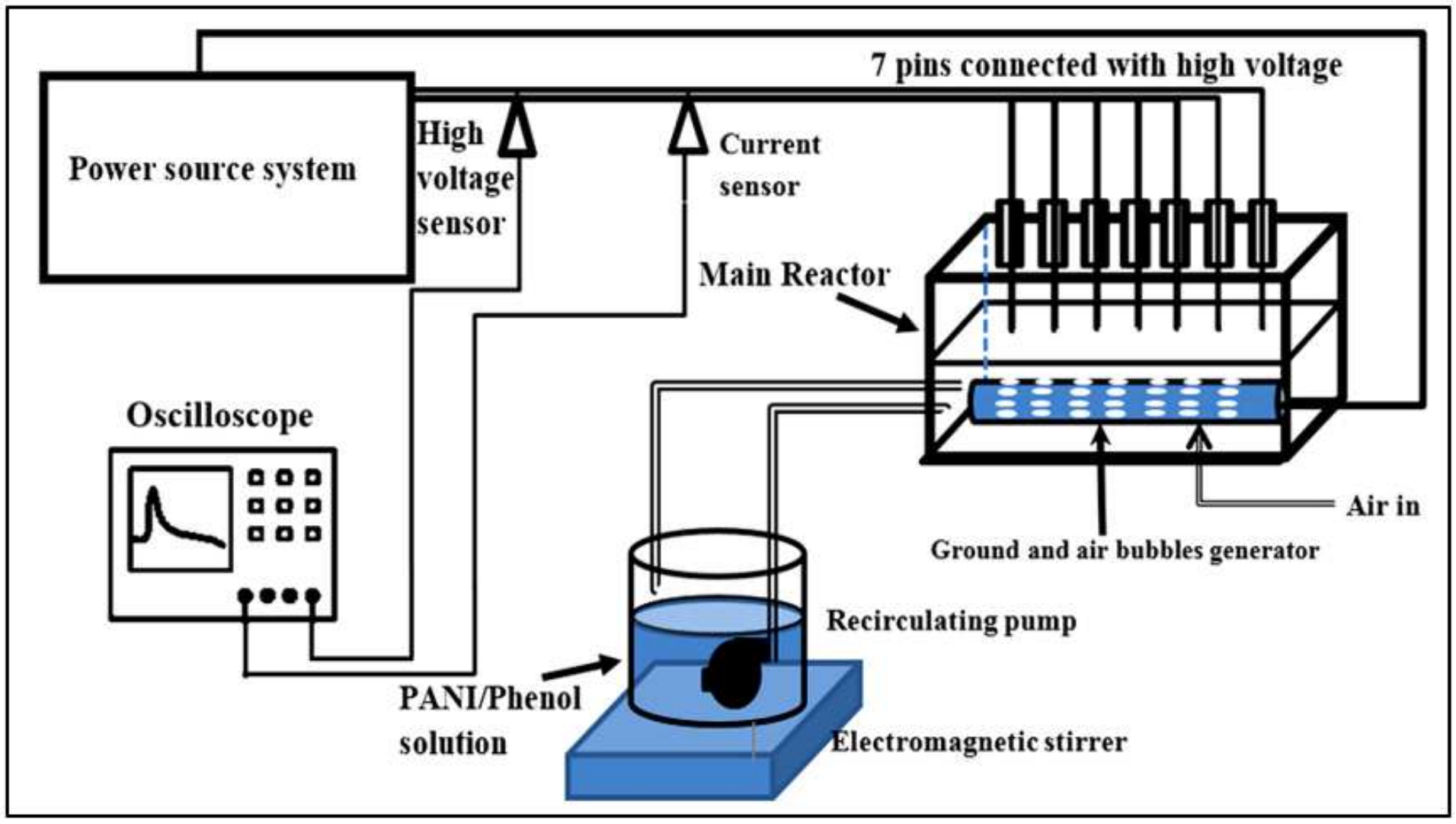

Figure 1

Schematic diagram of the designed new remediation system used for phenol removal.
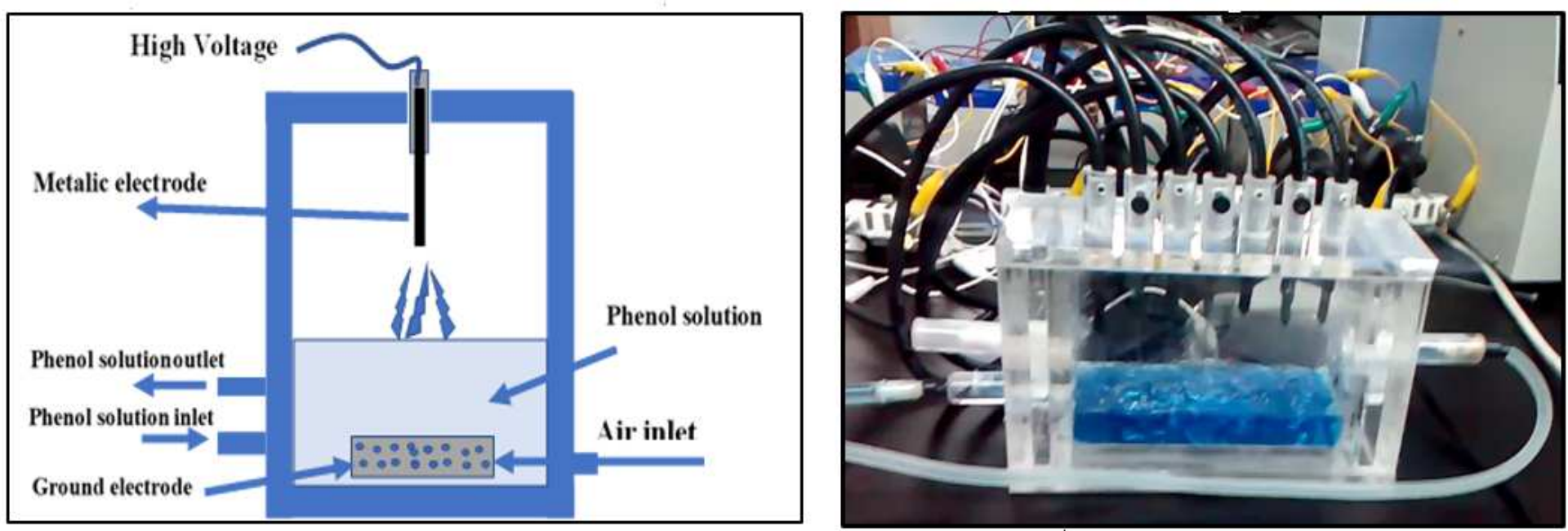

Figure 2

Schematic diagram of the main reactor's side view. 



Figure 3

(a) SEM image, (b) XRD, (c) FT-IR, and (d) N2 adsorption/desorption isotherm and pore size distribution for the produced PANI. 


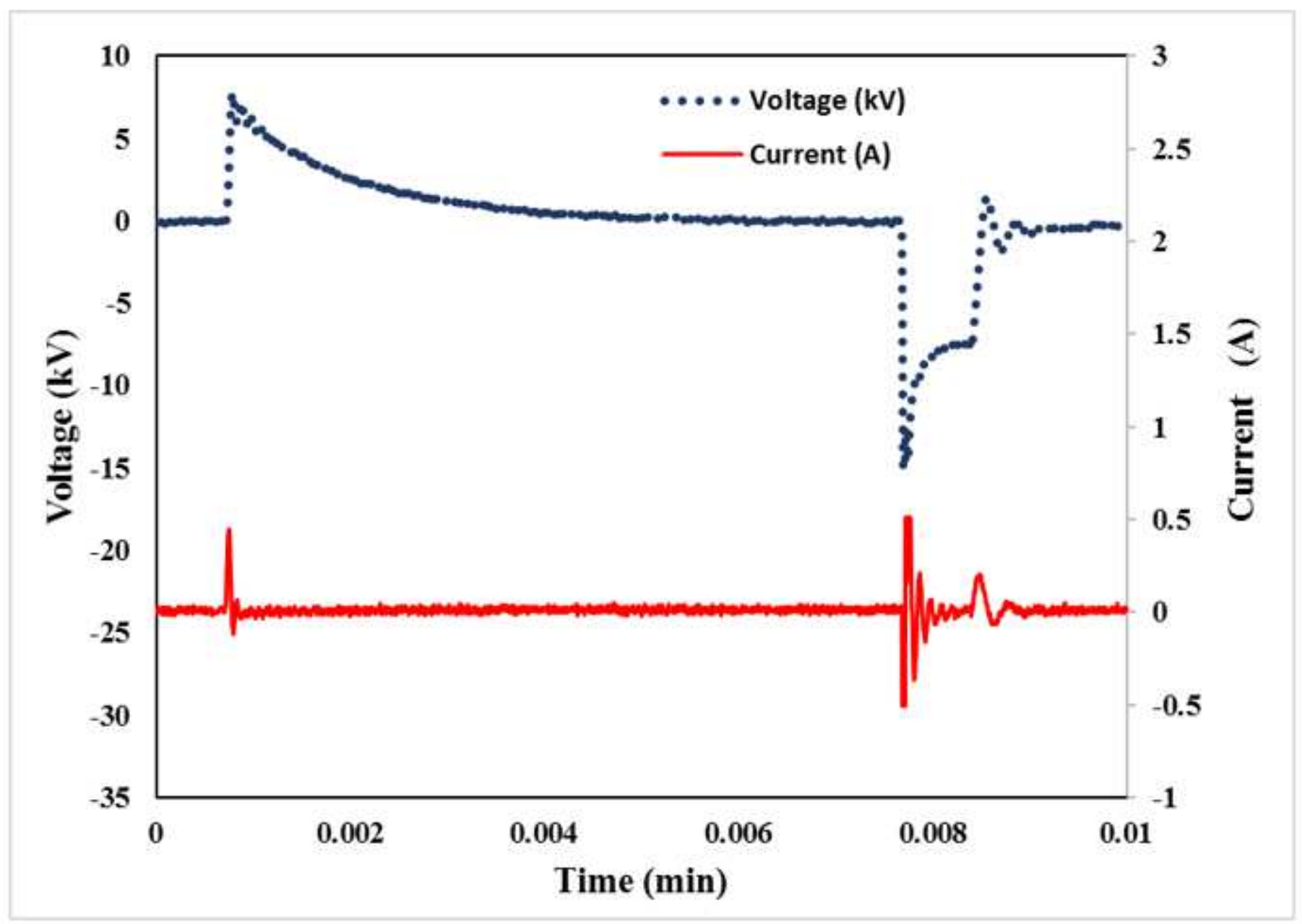

Figure 4

Signal used in Corona Discharge Plasma 


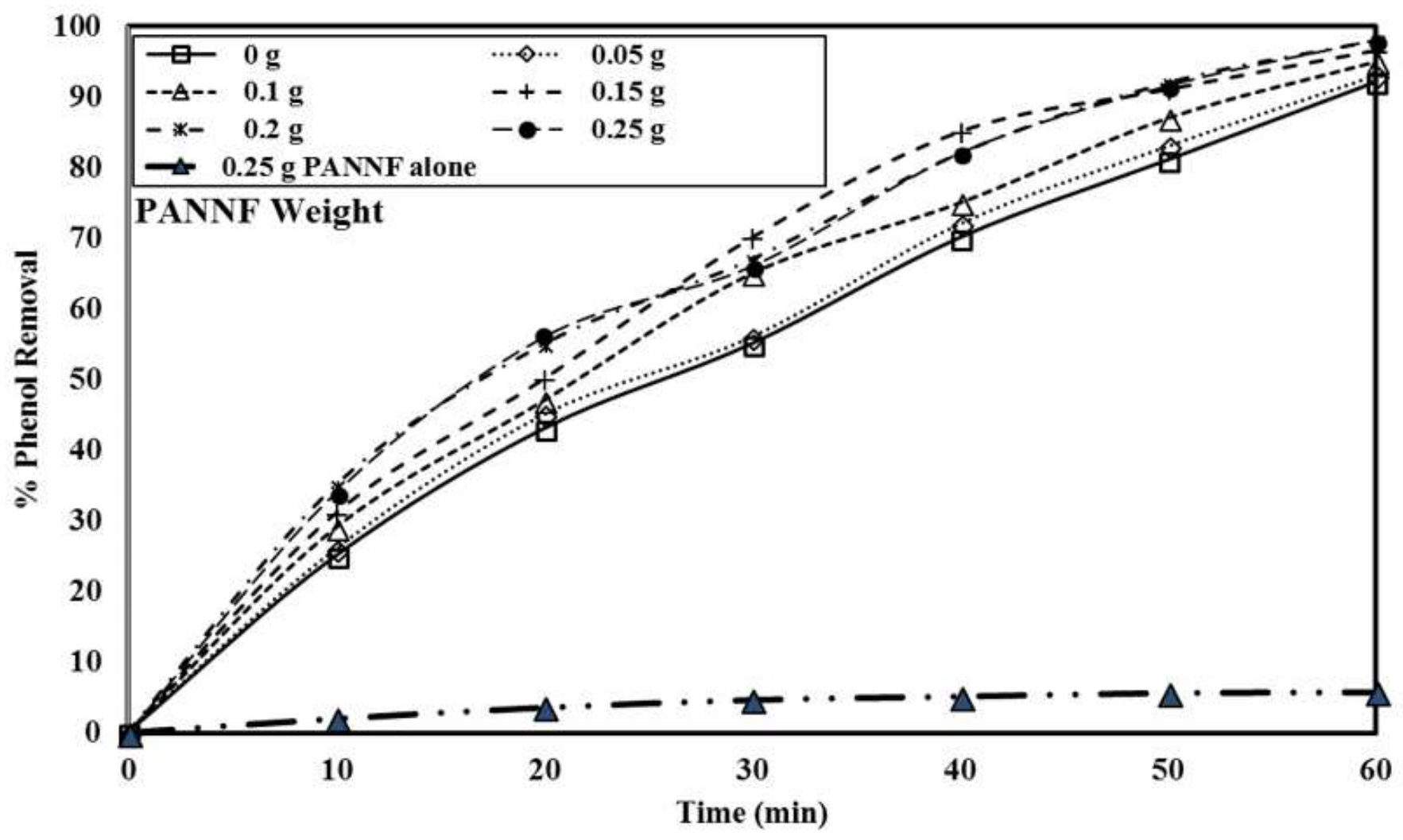

Figure 5

Phenol removal efficiency with different PANNF at initial phenol concentration of $20 \mathrm{mg} / \mathrm{L}$.

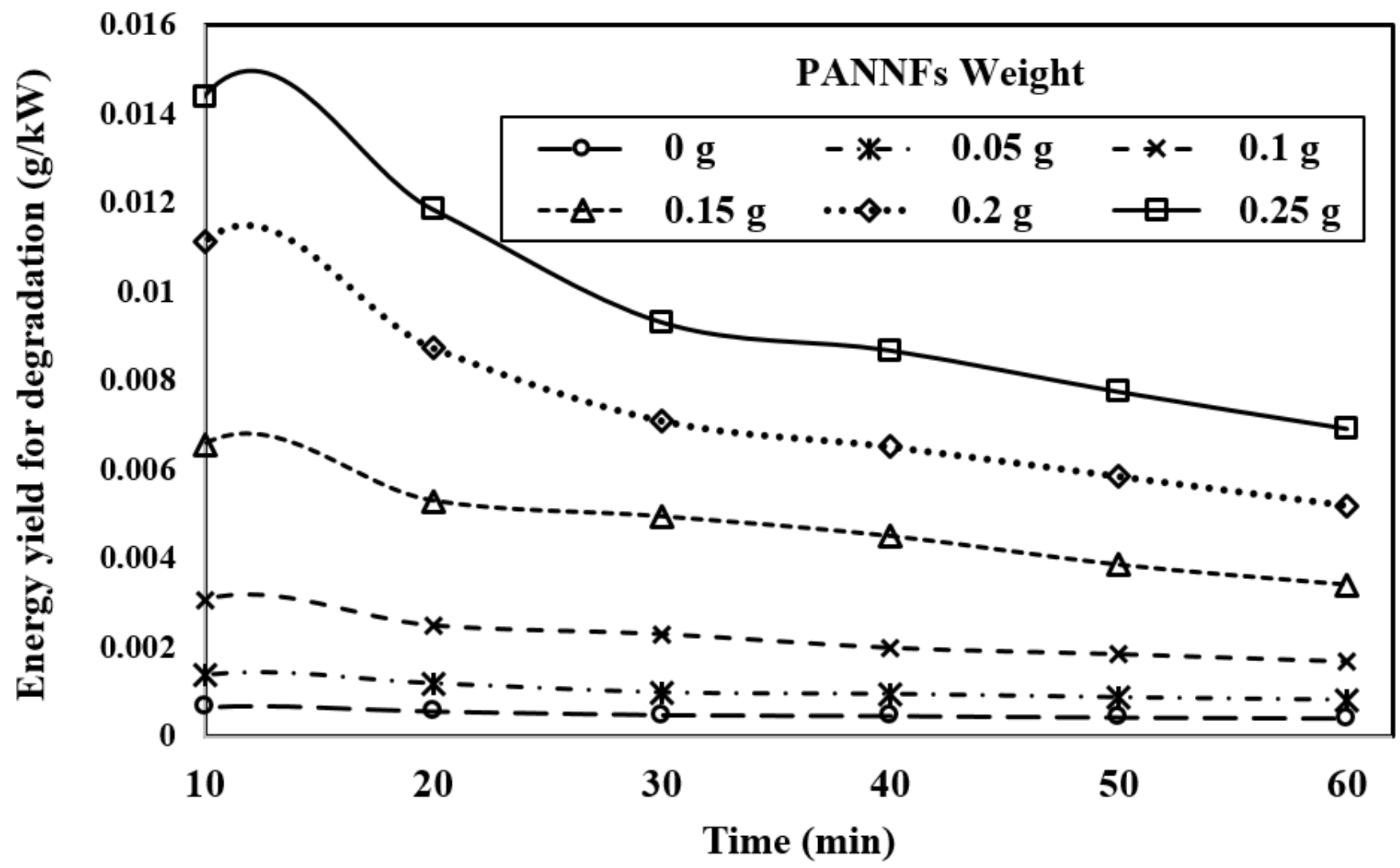


Figure 6

The energy yield with different PANNF amounts at initial phenol concentration of 20 [mg/L].



Figure 7

EE/O with different PANNF amounts at initial phenol concentration of $20 \mathrm{mg} / \mathrm{L}$. 


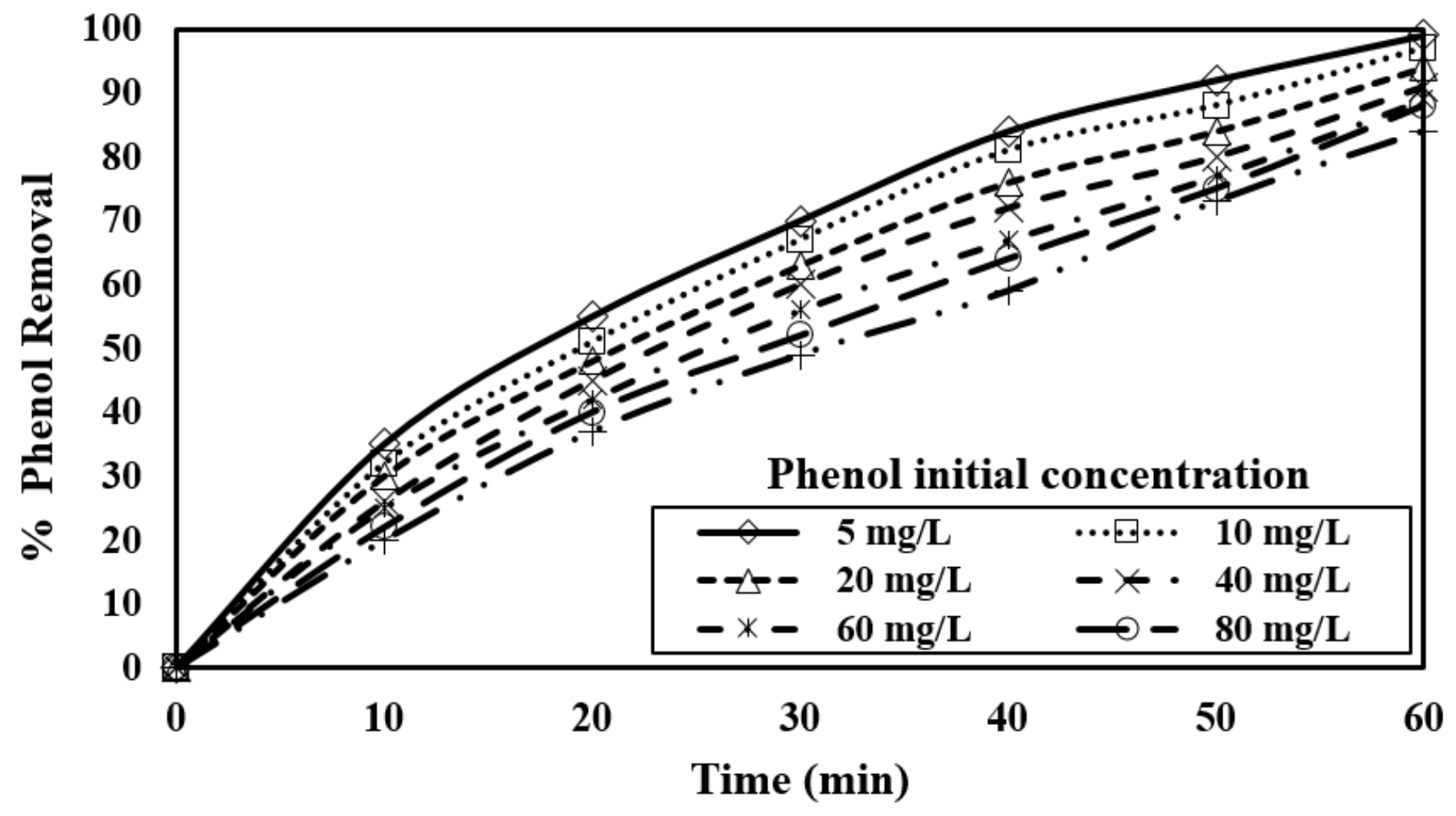

Figure 8

Phenol removal efficiency with different phenol concentration $0.2 \mathrm{~g}$ of PANNF.

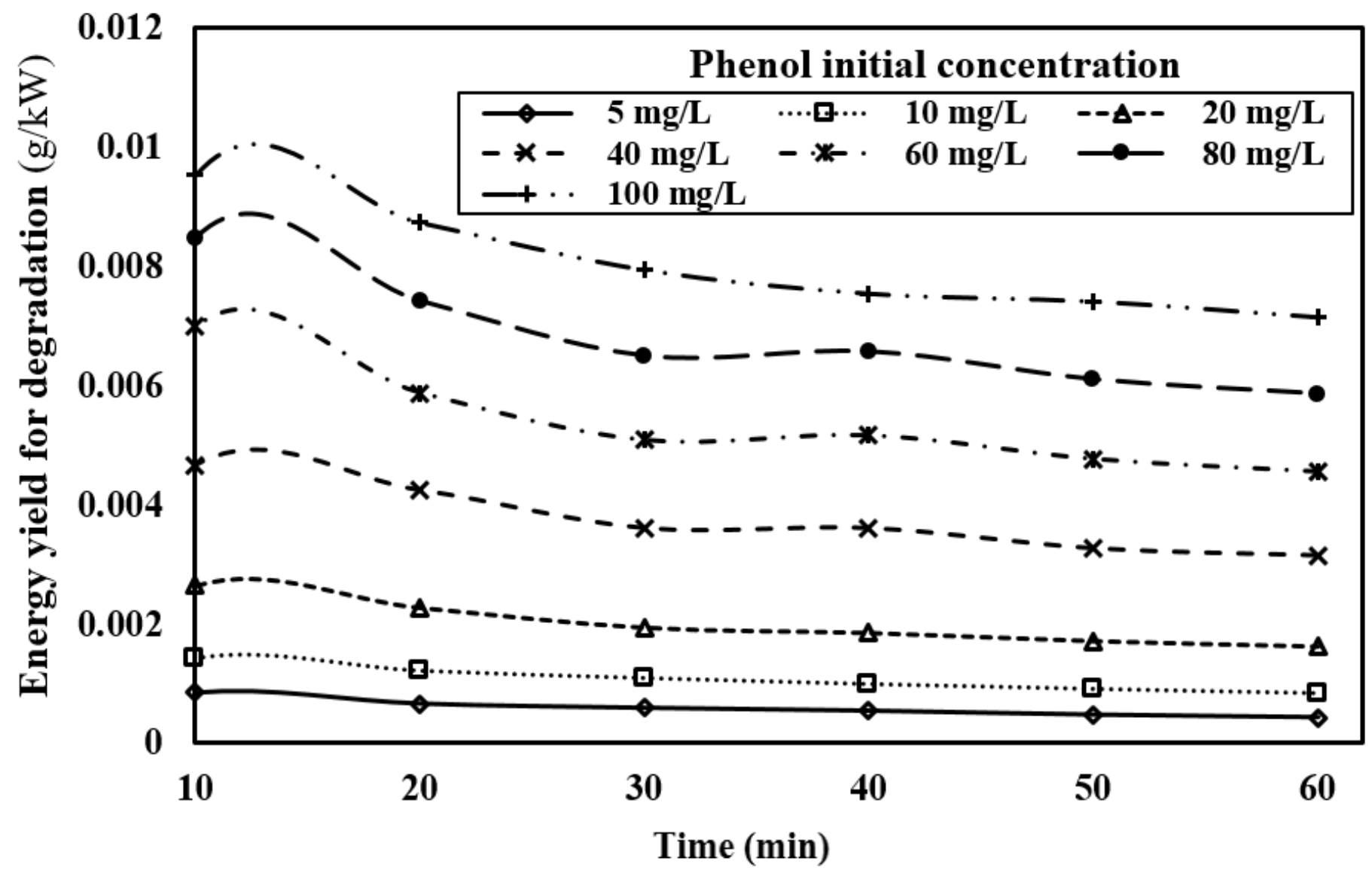


Figure 9

Energy yield of degradation with different phenol initial concentrations at $0.2 \mathrm{~g}$ of PANNF.



Figure 10

$\mathrm{EE} / \mathrm{O}$ with time at different phenol initial concentrations using $0.2 \mathrm{~g}$ of PANNF. 


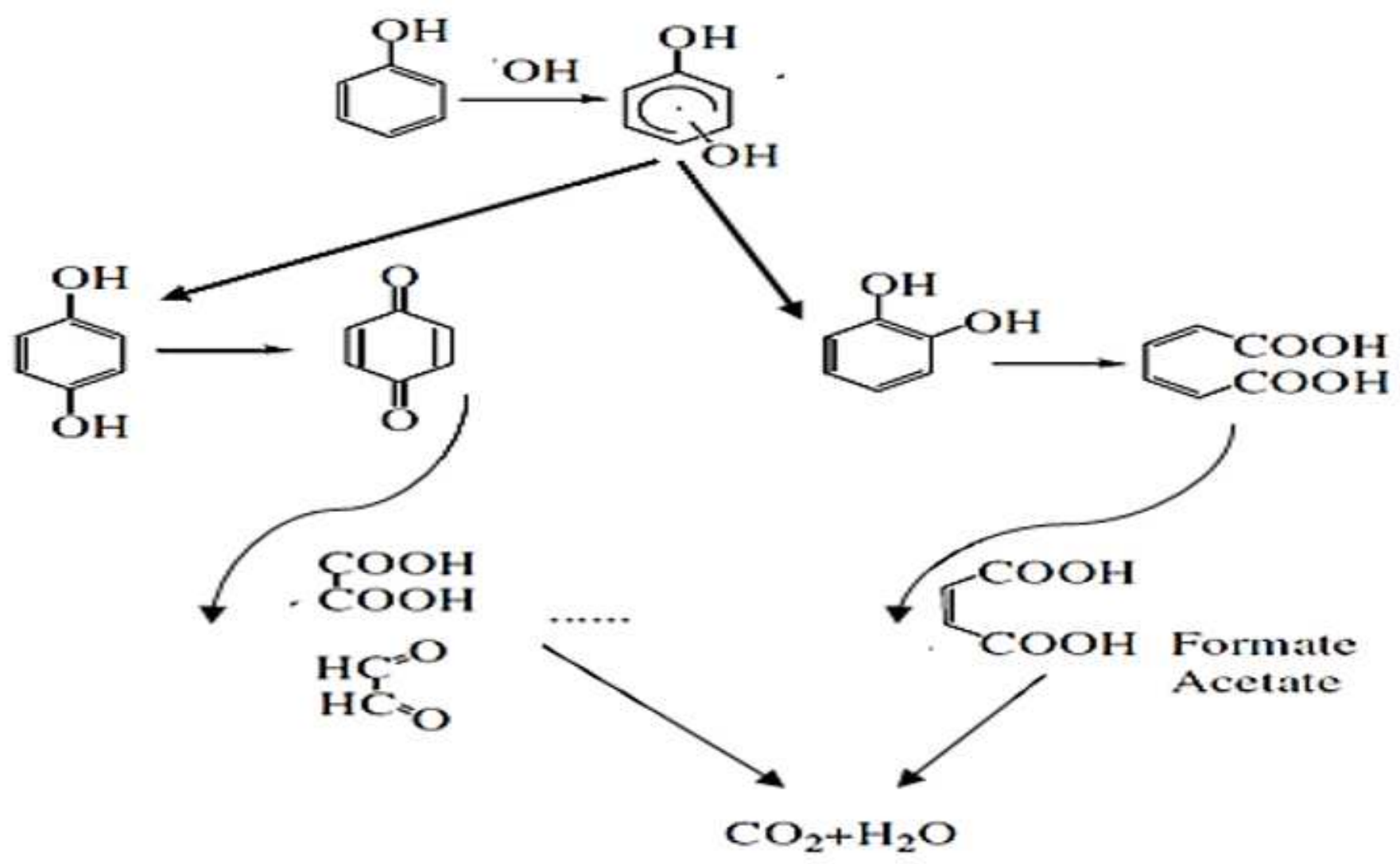

Figure 11

Schematic diagram for the proposed phenol degradation process mechanisms using the developed dual remediation system.

\section{Supplementary Files}

This is a list of supplementary files associated with this preprint. Click to download.

- GraphicalAbstarct.png 